\title{
Transgelin Protein Expression in Colorectal Cancer: A Clinicopathological Study.
}

\author{
Kota Amemiya ${ }^{1}$, Motohro Koma *2, Akiko Nagatuma ${ }^{2}$, Shingo Kawano ${ }^{1}$, Makoto Takahashi' \\ Hiromitu Komiyama ${ }^{1}$, Kazuhiro Sakamoto ${ }^{1}$, Atsushi Ocai ${ }^{2}$, Maski ito 3 \\ ${ }^{1}$ Department of Coloproctological Surgery, Juntendo University Faculty of Medicine, Juntendo University, Tokyo, \\ Japan \\ ${ }^{2}$ Division of Pathology, Research Center for Innovative Oncology, National Cancer Center Hospital East, Chiba, Japan \\ 3Department of Colorectal and Pelvic Surgery, National Cancer Center Hospital East, Chiba, Japan
}

\begin{abstract}
Transgelin is an actin-binding protein expressed in smooth muscle cells, cancer cells and fibroblasts. While Transgelin has previously been reported to be a tumor suppressor, recent studies have shown that Transgelin is involved in carcinogenesis, with its mRNA expression shown to be associated with poor prognosis in colorectal cancer. To date, however, very few clinicopathological studies have been conducted on Transgelin expression in colorectal cancer tissue. The aim of this study was therefore to elucidate the clinicopathological role of Transgelin expression in colorectal cancer and stromal cells. Ninety-six patients undergoing curative surgery for colorectal cancer between February and December 2012 were enrolled in this study, and immunostaining was performed to examine Transgelin expression in stromal and cancer cells from these patients. Fluorescent double immunostaining was also performed to investigate Transgelin expression in $\alpha$-SMA-positive, cancer-associated fibroblasts. Transgelin expression was predominately observed in cancer stroma, rather than in cancer cells or normal epithelial cells. While Transgelin expression was shown to be limited in pericryptal fibroblasts, it was shown to be extremely enhanced in stromal fibroblasts. Transgelin expression in cancer stroma was significantly associated with $T$ stage $(P<0.01)$ and relapse-free survival, while that in cancer cells was not associated with any of the clinicopathological features examined.

Again, while a-SMA and Transgelin were shown to be co-expressed in cancer-associated fibroblasts, Transgelin was shown to be predominantly expressed in cancer-associated fibroblasts rather than in cancer cells. Thus, Transgelin may represent a novel marker for cancer-associated fibroblasts.
\end{abstract}

Keywords: Clinicopathological, Colorectal cancer, Disease-free survival, Pathological, Transgelin

Accepted on December 04, 2018

\section{Introduction}

Transgelin is a cytoplasmic protein that is expressed at highest abundance in the smooth muscle cells (SMCs) and fibroblasts. Transgelin is mainly involved in the reconstitution of the actin cytoskeleton via TGF- $\beta$, but recent research has shown that Transgelin regulation is involved in the development of many cancers [1]. While Transgelin expression is reported to be decreased in colorectal cancer cells, it is reported to be upregulated in cancer tissue or blood serum [2]. Increased expression of Transgelin protein is also reported in other cancers [3-8]. We recently reported that Transgelin mRNA expression in colorectal cancer tissue was a poor prognostic factor and was enhanced by the stimulation of colonic fibroblasts [9-14]. Thus, the contradicting results reported for Transgelin expression may be associated with differences among the cell types evaluated [15]. However, to date, very few intensive immunohisotochemical investigations have been conducted on Transgelin protein expression. In this study, Transgelin protein expression was examined in normal and colorectal cancer tissues to investigate their clinicopathological associations. Transgelin expression was also intensively studied in both in cancer cells and stromal cells to elucidate its cell type-dependent biological function in cancer tissue.

\section{Material and Methods}

\section{Materials}

This study included a total of 96 consecutive patients undergoing curative surgery for colorectal cancer at the National Cancer Center East Hospital from February to December 2012 (Table 1). Patients receiving neoadjuvant therapy were excluded from this study. The study subjects' clinical data and other information were collected from the hospital's electronic medical records. To follow up on their postoperative course, all subjects were instructed to present to the hospital once every four months for the first 2 years and once every 6 months for the following three years. At the time of follow-up, all subjects underwent chest, abdominal, pelvic CT examinations and blood sampling tests according to the protocol of the Japan Colon Cancer Research Group. In 
Citation: Amemiya K,Kojima M,Nagatuma A, et al.. Transgelin Protein Expression in Colorectal Cancer: A Clinicopathological Study. Allied J Clin Oncol Cancer Res 2018;1(1):23-34.

addition, all subjects underwent lower gastrointestinal endoscopy in the 2nd and 5th postoperative years and were instructed to present to the hospital once a year after 5 years of follow-up. All experiments were performed after obtaining comprehensive written informed consent from all subjects. This study was approved by the National Cancer Hospital Ethical Review Board (No. 2012-067) and was performed in accordance with relevant guidelines and regulations.

Table 1. Patient Characteristics

\begin{tabular}{|c|c|c|}
\hline$N=96$ & & Number (\%) \\
\hline \multirow[t]{2}{*}{ Age } & $65 y>$ & $38(39.6 \%)$ \\
\hline & $65 y<$ & $58(60.4 \%)$ \\
\hline \multirow[t]{2}{*}{ Sex } & Male & $64(66.7 \%)$ \\
\hline & Female & $32(33.3 \%)$ \\
\hline \multirow[t]{2}{*}{ Tumor location } & Colon & $51(53.1 \%)$ \\
\hline & Rectum & $45(46.9 \%)$ \\
\hline \multirow[t]{4}{*}{ pStage } & 1 & $21(21.9 \%)$ \\
\hline & ॥ & $34(35.4 \%)$ \\
\hline & III & $37(38.5 \%)$ \\
\hline & IV & $4(4.2 \%)$ \\
\hline \multirow[t]{3}{*}{ Histologic type } & Well or moderate & $88(91.7 \%)$ \\
\hline & Poor & $3(3.1 \%)$ \\
\hline & Muc & $5(5.2 \%)$ \\
\hline \multirow[t]{4}{*}{ T stage } & $\mathrm{T} 1$ & $6(6.3 \%)$ \\
\hline & $\mathrm{T} 2$ & $22(22.9 \%)$ \\
\hline & T3 & $56(58.3 \%)$ \\
\hline & $\mathrm{T} 4$ & $12(12.5 \%)$ \\
\hline \multirow[t]{2}{*}{ Lymph node metastasis } & Positive & $38(39.6 \%)$ \\
\hline & Negative & $58(60.4 \%)$ \\
\hline \multirow[t]{2}{*}{ Distant metastasis } & Positive & $4(4.2 \%)$ \\
\hline & Negative & $92(95.8 \%)$ \\
\hline \multirow[t]{2}{*}{ Lymphatic invasion } & Positive & $54(56.2 \%)$ \\
\hline & Negative & $42(43.8 \%)$ \\
\hline \multirow[t]{2}{*}{ Venous invasion } & Positive & $71(74.0 \%)$ \\
\hline & Negative & $25(26.0 \%)$ \\
\hline \multirow[t]{2}{*}{ Neural invasion } & Positive & $22(22.9 \%)$ \\
\hline & Negative & $74(77.1 \%)$ \\
\hline \multirow[t]{2}{*}{ Tumor budding } & Grade 2 and 3 & $50(52.1 \%)$ \\
\hline & Grade 1 & $46(47.9 \%)$ \\
\hline \multirow[t]{2}{*}{ Poorly differentiated alveoar } & Grade 2 and 3 & $47(49.0 \%)$ \\
\hline & Grade 1 & $49(51.0 \%)$ \\
\hline \multirow[t]{2}{*}{ ELI(Colon) } & Positive & $34(66.7 \%)$ \\
\hline & Negative & $17(33.3 \%)$ \\
\hline
\end{tabular}

\section{Histologic evaluation}

Tumor stage was assessed using the UICC TNM classification system (7th edition). Formalin-fixed paraffin-embedded specimens from the colorectal cancer tissue were cut into 3 $\mu \mathrm{m}$-thick serial sections to perform histological, immunohistochemical, and immunofluorescent analysis. Hematoxylin and eosin ( $\mathrm{H} \& \mathrm{E})$ slides were used for histological analysis. Immunohistochemical staining for Transgelin and $\alpha$-SMA was carried out automatically by using Ventana Benchmark ULTRA (Ventana Medical Systems, AZ, USA) to ensure uniform results using mouse monoclonal antihuman Transgelin antibody (OriGene Technologies, Maryland, USA; at a dilution of 1:800) as a primary antibody. Similarly, monoclonal anti-human $\alpha$-SMA antibody (Dako, Glostrup, Denmark, at a dilution of 1:500) were used as a primary antibody for immunostaining of $\alpha$-SMA. Ultra View Universal HRP Multimer (Roche, Arizona, USA) was used for Transgelin and NIEW Biotinylated Ig Secondary Antibody (Roche, Arizona, USA) was used for $\alpha$-SMA as secondary antibodies. Stained slides were photographed using NanoZoomer Digital Pathology Virtual Slide Scanner (Hamamatsu Photonics, Hamamatsu, Japan), and were observed using viewer software (NDP view; Hamamatsu photonics, Hamamatsu, Japan). Transgelin protein expression $>$ $10 \%$ in normal epithelial cells and cancer cells was interpreted as positive, as previously reported (Figure 1) and all assessments were performed by one investigator under the supervision of experienced pathologists. Transgelin and $\alpha$ SMA protein expression was evaluated in cancer stroma by using morphometric software (WinRoof, Mitani Corporation, Fukui, Japan). Photographs of immunohistochemical slides were obtained from a virtual slide file with $\times 20$ magnification and $1368 \times 768$ pixels. Six photographs were obtained for each Trangelin-expressing tumor stroma without cancer cells and Trangelin-expressing smooth muscle cells. The Transgelinpositivity rate was assessed in all photographed areas as previously reported (Figure 2).

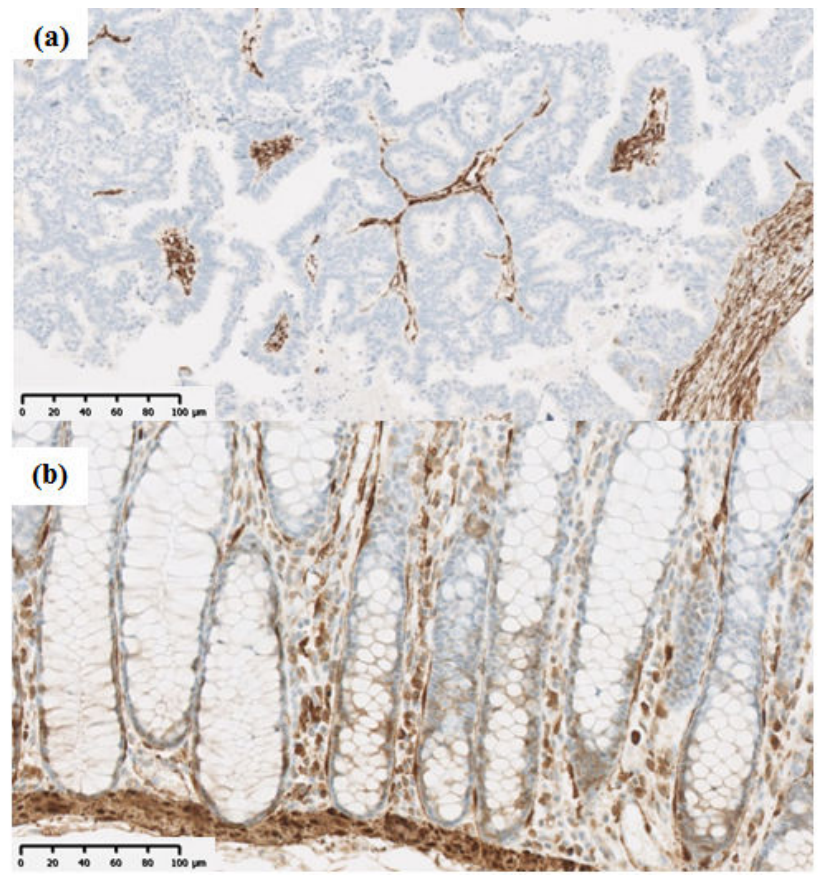

Figure 1. Evaluation method for transgelin expression in cancer stroma, epithelial and cancer cells: (a) negative (<10\%); (b) positive $(\geq 10 \%)$. 


\section{Examination for differences and similarities between Transgelin and $\alpha-S M A$ expression}

Fluorescence double staining was carried out to examine Transgelin and $\alpha$-SMA expression for similarities. As primary antibodies, mouse monoclonal anti-human Tansgelin antibody (OriGene Technologies, Maryland, USA; at dilution of 1:200) and rabbit monoclonal anti-human $\alpha$-SMA (SPRING
BIOSCIENCE, Arizona, USA; at a dilution of 1:200) were used. As secondary antibodies, Alexa Fluor 546 goat antimouse IgG (Life Technologies Corporation, Oregon, USA) was used for Trangelin and Alexa Fluor 488 goat anti- rabbit IgG (Life Technologies Corporation, Oregon, USA) was used for $\alpha$-SMA. Protein localization was examined using an all-inone fluorescence microscope (Keyence, Osaka, Japan).
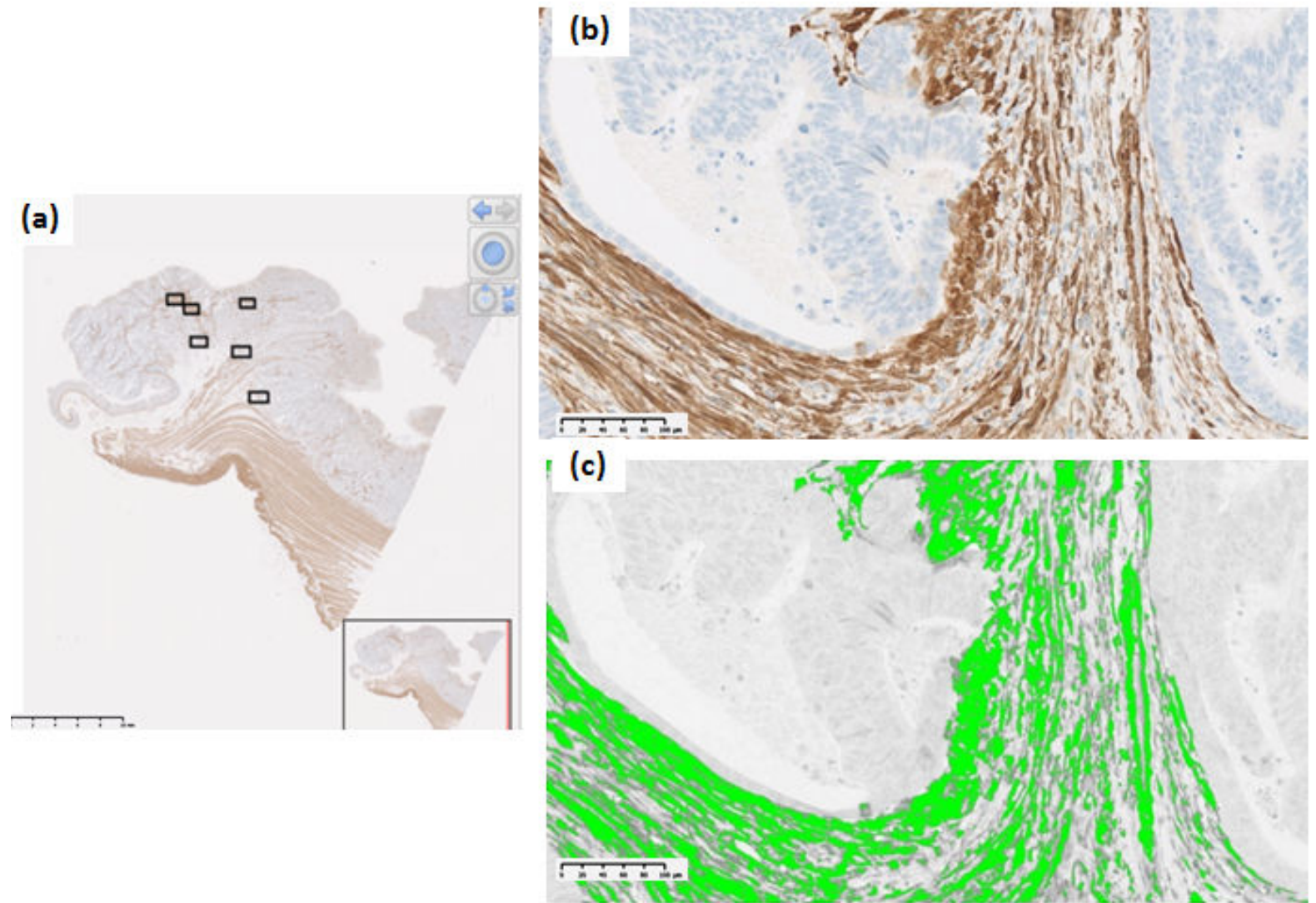

Figure 2. Evaluation method for transgelin expression in cancer stroma, epithelial and cancer cells: (a) six photographs were obtained for each tumor stroma without epithelial cells, cancer cells, and smooth muscle cells; (b) all photographs were converted to JPEG images; and (c) the rate of transgelin expression was calculated for all positive areas using computer software.

\section{Statistical analysis}

Transgelin expression and clinicopathological features were examined for association by the Mann-Whitney $U$ test. The cut-off value for each material was determined using the ROC curve. Transgeln and the area of $\alpha$-SMA were evaluated for correlation using Spearman's rank correlation coefficient " $r$ ". DFS was calculated using the Kaplan-Meier method. All analyses were performed using JMP version 13.0.0 (SAS Institute Cary, NC, USA). All calculated P values were twotailed and $\mathrm{P}$ values $<0.05$ were considered statistically significant.

\section{Result}

\section{Transgelin expression in normal epithelial cells and cancer cells}

Transgelin expression was confirmed and assessed in normal epithelial cells adjacent to cancer tissue from 68 subjects
(Table 2). Transgelin expression was shown to be positive in normal epithelial cells from 9 subjects $(13.2 \%)$ and negative in those from 59 subjects $(86.8 \%)$, while it was shown to be positive in cancer cells from 15 subjects $(15.6 \%)$ and negative in those from 81 subjects $(84.4 \%)$. Furthermore, Transgelin expression was weakly intensive in stromal cells (Figure 3). No decreases in Transgelin protein expression were confirmed in cancer cells.

Table 2. Staining positive rate by each organization of Transgelin.

\begin{tabular}{|l|l|l|l|}
\hline & N & Negative (10\%) & Positive (10\%) \\
\hline Normal epithelial cells & 68 & $59(86.8 \%)$ & $9(13.2 \%)$ \\
\hline Cancer cells & 96 & $81(84.4 \%)$ & $15(15.6 \%)$ \\
\hline
\end{tabular}


Citation: Amemiya K,Kojima M,Nagatuma A, et al.. Transgelin Protein Expression in Colorectal Cancer: A Clinicopathological Study. Allied J Clin Oncol Cancer Res 2018;1(1):23-34.
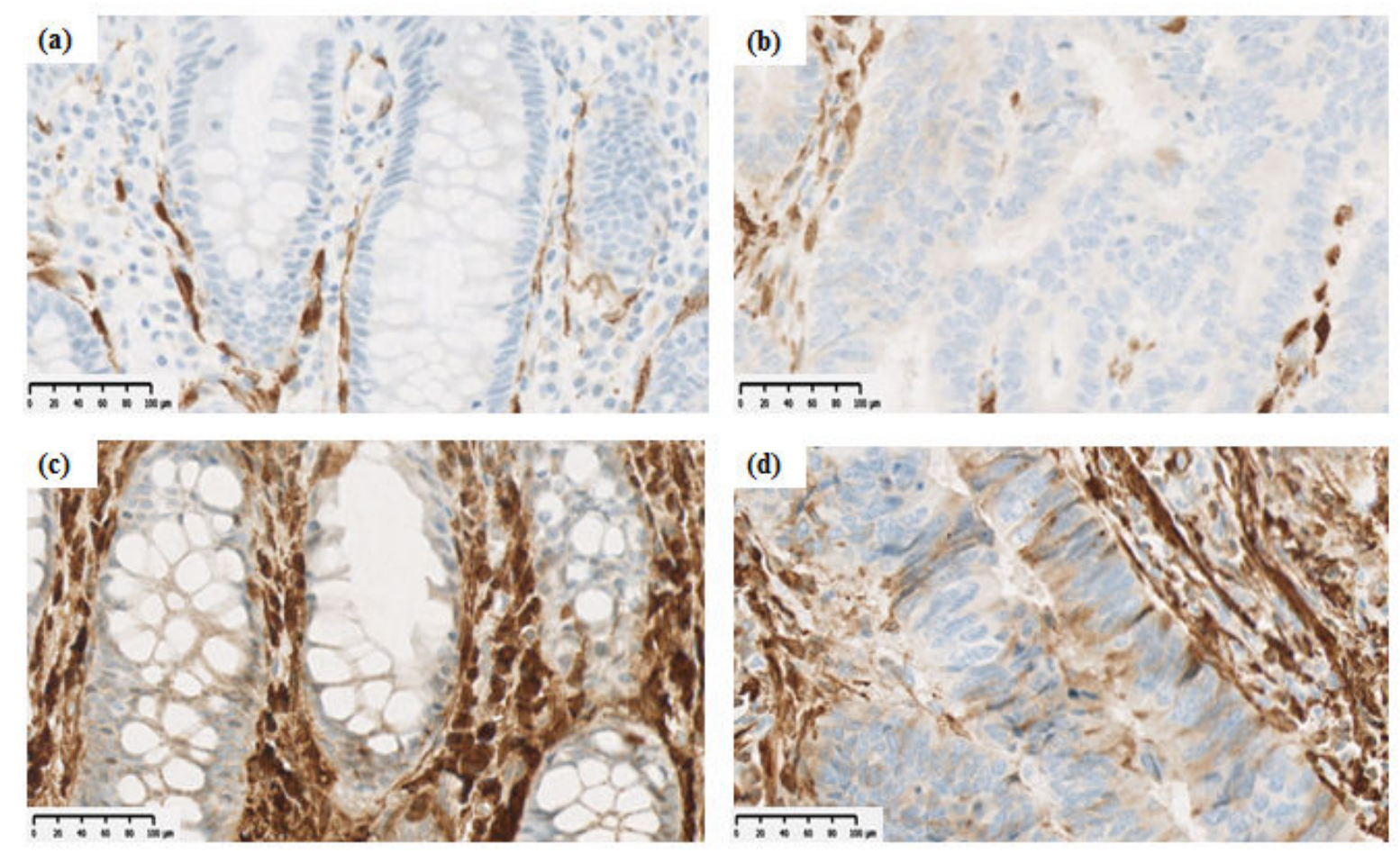

Figure 3. Transgelin expression in epithelial and cancer cells: (a) negative epithelial cells; (b) negative cancer cells; (c) positive epithelial cells; and (d) positive cancer cells.

\section{Transgelin expression in normal stromal fibroblasts and cancer stromal fibroblasts}

Transgelin expression was shown to be broader and more intensive in normal smooth muscle tissue and cancer stroma than in epithelial and cancer cells (Figure 4). In normal stroma, Transgelin was shown to be strongly expressed at all times in smooth muscle cells, while it was shown to be consistently expressed in pericryptal fibroblasts. Transgelin expression was shown to be markedly upregulated in cancer stromal spindle cells, consistently with that in cancer stromal fibroblasts.
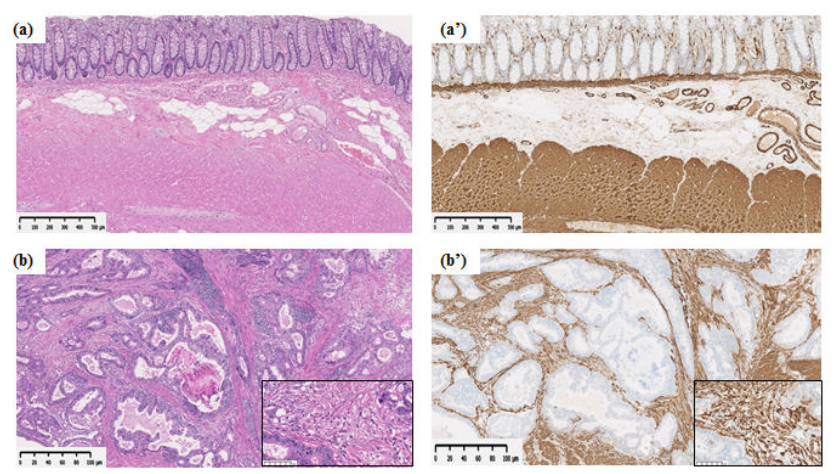

Figure 4. (a)/(a') Relationship between HE staining and TAGLN staining (smooth muscle cells); (b)/ (b') relationship between HE staining and TAGLN staining (cancer tissue: left, $\times 10$; right, $\times 20$ ).

\section{Relationship between Transgelin protein expression in cancer cells and cancer stroma}

Transgelin expression in cancer cells and cancer stroma was examined for association with relevant clinicopathological features (Table 3). Transgelin expression in cancer cells was associated with none of the clinicopathological features evaluated. Again, Transgelin expression in cancer stroma was shown to be positive in $20.78 \%$ of the tumor areas examined, and was shown to be significantly associated with $\mathrm{T}$ stage $(\mathrm{P}<$ 0.05). Further, all cancer cells and cancer stroma were evaluated for Transgelin protein expression and relapse-freesurvival (RFS) (Figure 5). Transgelin expression in cancer cells was not shown to be associated with clinical outcomes, while that in cancer stroma was shown to be associated with poor RFS $(\mathrm{P}<0.05)$.

\section{Association between stromal Transgelin and $\alpha-S M A$ expression}

$\alpha$-SMA is known to be expressed in cancer-associated fibroblasts with its expression shown to be associated with poor prognosis. Stromal Transgelin expression and $\alpha$-SMA (known as a marker of cancer-associated fibroblasts [CAF]) were examined for association. Transglein-positive areas were shown to be strongly correlated with $\alpha$-SMA-positive areas in cancer tissue (Figure 6). Double labelling-immunofluorescent examination revealed co-expression of Transgelin and $\alpha$-SMA 
in CAF (Figure 7). Thus, Transgelin expression was shown to

be predominant in $\mathrm{CAF}$ in human colorectal cancer tissue.

Table 3. In Transgelin of Tumor stroma and cells, the results of tests by area ratio for each charactarestics.

\begin{tabular}{|c|c|c|c|c|c|c|}
\hline & & & Tumor Stroma & & Tumor Cells & \\
\hline Characteristics & & $\begin{array}{l}\text { No. of patients } \\
(\%)\end{array}$ & $\begin{array}{l}\text { Positive area(\%, median, } \\
\text { min-max) }\end{array}$ & & $\begin{array}{l}\text { Ratio(Grade2: } \\
\text { Grade0,1) }\end{array}$ & \\
\hline Total & & 96 & & & & \\
\hline Age & $\begin{array}{l}<65 \\
>65\end{array}$ & $\begin{array}{l}38(39.6) \\
58(60.4)\end{array}$ & $\begin{array}{l}20.3(7.4 \sim 34.5) \\
21.1(8.1 \sim 35.2)\end{array}$ & 0.96 & $\begin{array}{l}\text { 06:32:00 } \\
\text { 09:42:00 }\end{array}$ & 0.97 \\
\hline Sex & $\begin{array}{l}\text { Male } \\
\text { Female }\end{array}$ & $\begin{array}{l}64(66.7) \\
32(33.3)\end{array}$ & $\begin{array}{l}21.0(8.1-35.2) \\
20.4(7.4-30.7)\end{array}$ & 0.55 & $\begin{array}{l}\text { 10:54:00 } \\
\text { 05:27:00 }\end{array}$ & 1.00 \\
\hline Tumor location & $\begin{array}{l}\text { Colon } \\
\text { Rectum }\end{array}$ & $\begin{array}{l}51(53.1) \\
45(46.9)\end{array}$ & $\begin{array}{l}20.3(8.1-30.3) \\
21.9(7.4-35.2)\end{array}$ & 0.08 & $\begin{array}{l}\text { 05:46:00 } \\
\text { 10:35:00 }\end{array}$ & 0.09 \\
\hline Tumor size (mm) & $\begin{array}{l}40 \mathrm{~mm}< \\
<40 \mathrm{~mm}\end{array}$ & $\begin{array}{l}45(46.9) \\
51(53.1)\end{array}$ & $\begin{array}{l}21.3(7.4-34.5) \\
20.1(8.1-35.2)\end{array}$ & 0.17 & $\begin{array}{l}\text { 10:35:00 } \\
\text { 05:46:00 }\end{array}$ & 0.09 \\
\hline T Stage & $\begin{array}{l}\mathrm{T} 1 \\
\mathrm{~T} 2 \\
\mathrm{~T} 3 \\
\mathrm{~T} 4\end{array}$ & $\begin{array}{l}6(6.3) \\
22(22.9) \\
56(58.3) \\
12(12.5)\end{array}$ & $\begin{array}{l}18.8(12.0-35.2) \\
21.7(7.4-34.5)\end{array}$ & $<0.01^{*}$ & $\begin{array}{l}\text { 02:26:00 } \\
\text { 13:55:00 }\end{array}$ & 0.14 \\
\hline Lymph node metastasis & $\begin{array}{l}\text { Positive } \\
\text { Negative }\end{array}$ & $\begin{array}{l}38(39.6) \\
58(60.4)\end{array}$ & $\begin{array}{l}21.5(7.4-33.5) \\
20.2(8.1-35.2)\end{array}$ & 0.26 & $\begin{array}{l}09: 29: 00 \\
06: 52: 00\end{array}$ & 0.07 \\
\hline Distant metastasis & $\begin{array}{l}\text { Positive } \\
\text { Negative }\end{array}$ & $\begin{array}{l}4(4.2) \\
92(95.8)\end{array}$ & $\begin{array}{l}21.6(19.4-34.5) \\
20.8(7.4-35.2)\end{array}$ & 0.35 & $\begin{array}{l}0: 4 \\
15: 77\end{array}$ & 0.38 \\
\hline Lymphatic invasion & $\begin{array}{l}\text { Positive } \\
\text { Negative }\end{array}$ & $\begin{array}{l}54(56.3) \\
42(43.7)\end{array}$ & $\begin{array}{l}21.0(7.4-33.5) \\
20.6(8.6-35.2)\end{array}$ & 0.63 & $\begin{array}{l}11: 43 \\
4: 38\end{array}$ & 0.15 \\
\hline Venous invasion & $\begin{array}{l}\text { Positive } \\
\text { Negative }\end{array}$ & $\begin{array}{l}71(74.0) \\
25(26.0)\end{array}$ & $\begin{array}{l}20.9(7.4-34.5) \\
20.6(14.4-35.2)\end{array}$ & 0.39 & $\begin{array}{l}12: 59 \\
3: 22\end{array}$ & 0.56 \\
\hline pStage & $\begin{array}{l}\text { I } \\
\text { II } \\
\text { III } \\
\text { IV }\end{array}$ & $\begin{array}{l}21(21.9) \\
34(35.4) \\
37(38,5) \\
4(4.2)\end{array}$ & $\begin{array}{l}18.0(14.4-35.2) \\
21.4(8.1-30.8) \\
21.3(7.4-33.5) \\
21.6(19.4-34.5)\end{array}$ & 0.13 & $\begin{array}{l}2: 19 \\
4: 30 \\
9: 28 \\
0: 4\end{array}$ & 0.28 \\
\hline Budding & $\begin{array}{l}\text { Grade } 2 \text { and } 3 \\
\text { Grade } 1\end{array}$ & $\begin{array}{l}50(52.1) \\
46(47.9)\end{array}$ & $\begin{array}{l}21.6(12.0-33.5) \\
20.3(7.4-35.2)\end{array}$ & 0.09 & $\begin{array}{l}11: 39 \\
4: 42\end{array}$ & 0.07 \\
\hline Poorly differentiated alveoar & $\begin{array}{l}\text { Grade } 2 \text { and } 3 \\
\text { Grade } 1\end{array}$ & $\begin{array}{l}47(49.0) \\
49(51.0)\end{array}$ & $\begin{array}{l}21.1(8.1-33.5) \\
20.6(7.4-35.2)\end{array}$ & 0.3 & $\begin{array}{l}10: 37 \\
5: 44\end{array}$ & 0.13 \\
\hline
\end{tabular}

\section{Discussion}

In this study, Transgelin protein expression was intensively examined for distribution in normal and cancerous tissues. Study results revealed that Transgelin is independently expressed in epithelial and stromal cells alike, while it is always predominant in stromal cells. Again, Transgelin was shown to be weakly expressed not only in epithelial cells but in cancer cells. Many studies reported downregulation of Transgelin in cancer cells, as compared to that in normal epithelial cells, with its downregulation in cancer cells also shown to be associated with poor prognosis. However, Transgelin was not shown to be downregulated in cancer cells in this study, with no association found between Transgelin expression in cancer cells and the clinicopathological features examined [3-8]. In contrast, while Transgelin expression was confirmed only in pericryptal fibroblasts in normal colonic tissue, it was shown to be much more enhanced in cancer stromal fibroblasts. Furthermore, a clinicopathological examination revealed that Transgelin expression in cancer stroma alone was significantly correlated with $\mathrm{T}$ stage and prognosis. 
Citation: Amemiya K,Kojima M,Nagatuma A, et al.. Transgelin Protein Expression in Colorectal Cancer: A Clinicopathological Study. Allied

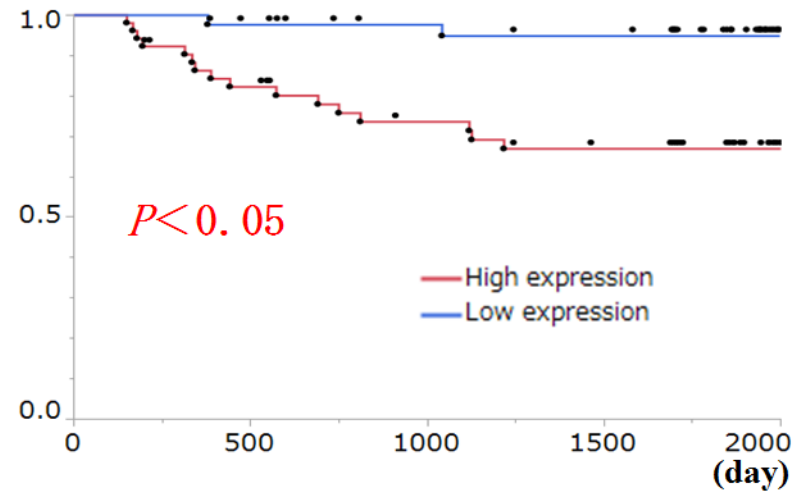

Cancer stroma

Figure 5. Relationship between relapse-free survival (RFS) and differences in intensity of trangelin expression in cancer stroma and cancer cells.

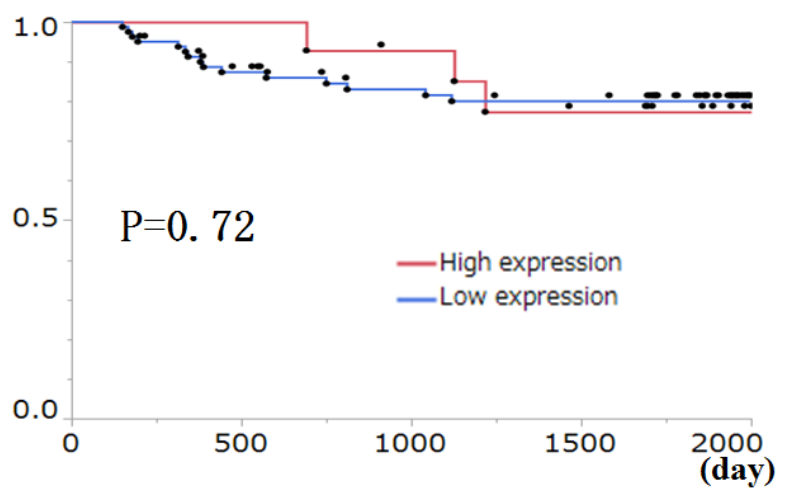

Cancer cells

Figure 6. Fluorescent staining of cancer tissue. $\alpha-S M A-$ and transgelin-positive cells shown in green and red, respectively. Shown on the lower right with increased magnification $(\times 20)$ is a composite fluorescent image of $\alpha$-SMA- and transgelin-positive cells (see a HE image of the same site on the lower left).
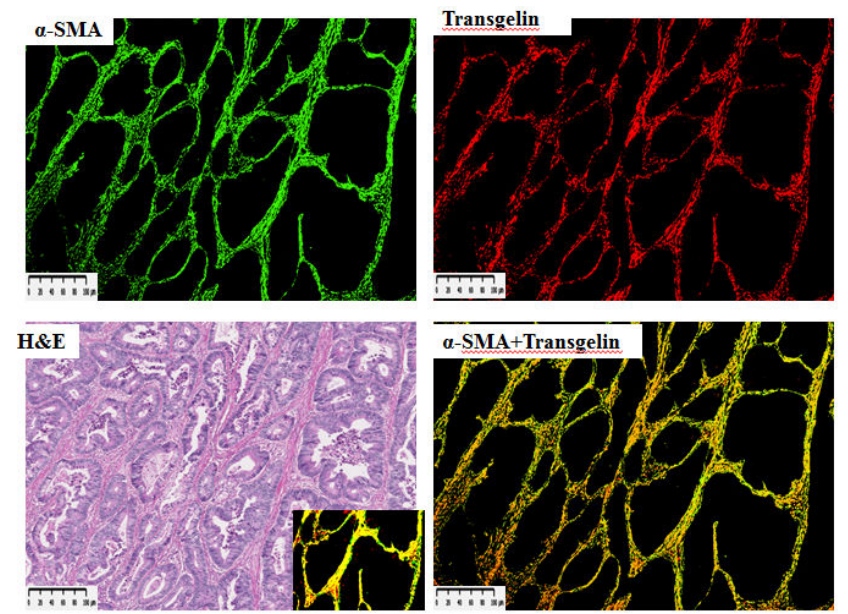

Figure 7. Relationship between transgelin positive rates and $\alpha-S M A$ positive rates.

These results suggest that transgelin expression in cancer stroma may have a more critical role to play in cancer progression and prognosis than that in cancer cells. We previously reported that genes upregulated in cultured colorectal fibroblasts after conditioned medium stimulation include various prognostic factors, including transgelin, one of the genes extracted from activated fibroblasts in microarray analysis. Therefore, it appears reasonable that Transgelin was shown to be overexpressed in activated fibroblasts in cancer stroma. In addition, we found that Transgelin expression in cancer stroma is associated with $\mathrm{T}$ stage and prognosis. A recent study also reported that Transgelin expression in tumor tissue or blood serum is associated with poor prognosis. Transgelin appears to call for further exploration as a potential prognostic marker.

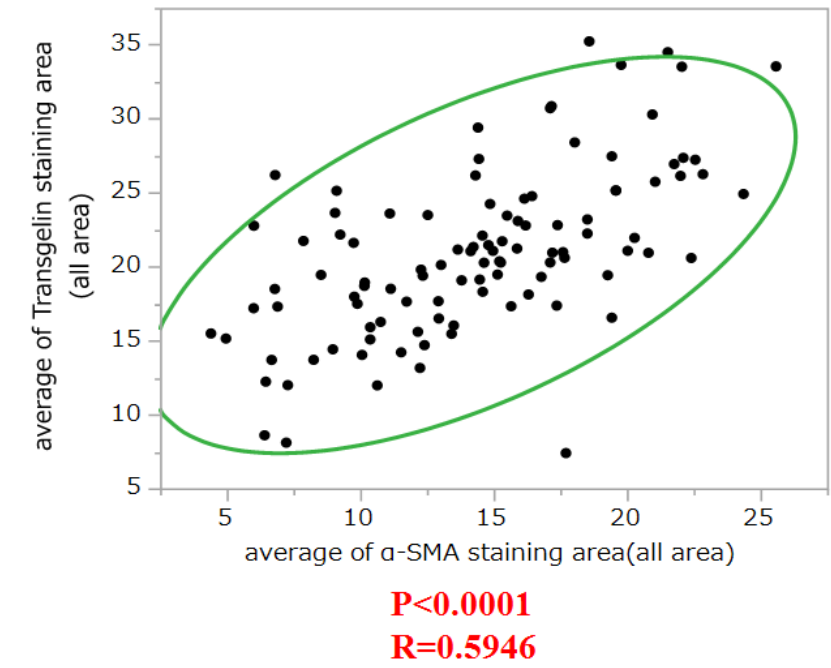

Figure 8. Average of Transgelin Staining area.

Given the strong association and co-expression of Transgelin with $\alpha$-SMA, Transgelin expression in cancer stroma may serve as a CAF marker, as well as a prognostic biomarker. Again, Transgelin, an actin-binding protein, may upregulate $\alpha$ SMA expression in colorectal cancer tissue. We earlier reported that $\alpha$-SMA expression was associated with tumor elasticity, which is in turn associated with clinical outcome, suggesting that mechanical properties of cancer tissue may have a role to play in regulating cancer cell migration as well as determining the malignant potential of cancer cells. Therefore, Transgelin expression in cancer stromal fibroblasts may be involved in the regulation of tumor stiffness through $\alpha$ SMA expression, thus enhancing the malignant behavior of tumor cells. Further bio-mechanical study is required to validate our study findings $[11,12,16,17]$.

\section{Conclusion}

In conclusion, Transgelin protein is predominantly expressed in cancer stromal fibroblasts and is associated with cancer progression and prognosis. Transgelin expression in cancer stroma may be used as a biomarker to predict prognosis as well as to identify CAF. Thus, intensive biological and biomechanical studies of Transgelin expression in cancer stromal fibroblasts are warranted. 


\section{Disclosure Statement}

The authors have no conflict of interest to declare.

\section{References}

1. Shapland C, Lowings P, Lawson D. Identification of new actin-associated polypeptides that are modified by viral transformation and changes in cell shape. J Cell Biol. 1988;107(1):153-161.

2. Dvorakova M, Nenutil R, Bouchal P. Transgelins, cytoskeletal proteins implicated in different aspects of cancer development. Expert Rev Proteomics. 2014;11(2): 149-165.

3. Shields JM, Rogers-Graham K, Der CJ. Loss of transgelin in breast and colon tumors and in RIE-1 cells by Ras deregulation of gene expression through Raf-independent pathways. J Biol Chem. 2002;277(12):9790-9799.

4. Peng J, Zhang Q, Ma Y, et al. A rat-to-human search for proteomic alterations reveals transgelin as a biomarker relevant to colorectal carcinogenesis and liver metastasis. Lectrophoresis. 2009;30(17):2976-87.

5. Yeo M, Kim DK, Park HJ, et al. Loss of transgelin in repeated bouts of ulcerative colitis-induced colon carcinogenesis. Proteomics. 2006;6(4):1158-65.

6. Zhao L, Wang H, Deng YJ, et al. Transgelin as a suppressor is associated with poor prognosis in colorectal carcinoma patients. Mod Pathol. 2009;22(6):786-96.

7. Yeo M, Park HJ, Kim DK, et al. Loss of SM22 is a characteristic signature of colon carcinogenesis and its restoration suppresses colon tumorigenicity in vivo and in vitro. Cancer. 2010;116(11):2581-89.

8. Li SY, An P, Cai HY, et al. Proteomic analysis of differentially expressed proteins involving in liver metastasis of human colorectal carcinoma. Hepatobiliary Panreat Dis Int. 2010;9(2):149-53.

9. Huang Q, Huang Q, Chen $\mathrm{W}$, et al. Identification of transgelin as a potential novel biomarker for gastric adenocarcinoma based on proteomics technology. J Cancer Res Clin Oncol. 2008;134(11):1219-27.

10. Ryu JW, Kim HJ, Lee YS, et al. The proteomics approach to find biomarkers in gastric cancer. J Korean Med Sci. 2003;18(4):505-09.

11. Li N, Zhang J, Liang Y, et al. A controversial tumor marker: is SM22 a proper biomarker for gastric cancer cells. J Proteome Res. 2007;6(8):3304-12.
12. Mikuriya K, Kuramitsu Y, Ryozawa S, et al. Expression of glycolytic enzymes is increased in pancreatic cancerous tissues as evidenced by proteomic profiling by twodimensional electrophoresis and liquid chromatographymass spectrometry/mass spectrometry. Int $\mathrm{J}$ Oncol. 2007;30(4):849-55.

13. Qi Y, Chiu JF, Wang L, Kwong DLW, et al. Comparative proteomic analysis of esophageal squamous cell carcinoma. Proteomics. 2005;5(11):2960-71.

14. Harada T, Kuramitsu Y, Makino A, et al. Expression of tropomyosin alpha 4 chain is increased in esophageal squamous cell carcinoma as evidenced by proteomic profiling by two-dimensional electrophoresis and liquid chromatography-mass spectrometry/mass spectrometry. Proteomics Clin Appl. 2007;1(2):215-23.

15. Yokota M, Kojima M, Higuchi Y, et al. Gene expression profile in the activation of subperitoneal fibroblasts reflects prognosis of patients with colon cancer. Int $\mathrm{J}$ Cancer. 2016;138:1422-31.

16. Zhang J, Song MQ, Zhu JS, et al. Identification of differentially-expressed proteins between early submucosal non-invasive and invasive colorectal cancer using 2D-DIGE and mass spectrometry. Int $\mathrm{J}$ Immunopathol Pharmacol. 2011;24(4):849-59.

17. Rho JH, Roehrl MHA, Wang JY. Tissue proteomics reveals differential and compartment-specific expression of the homologs transgelin and transgelin-2 in lung adenocarcinoma and its stroma. J Proteome Res. 2009;8(12):5610-18.

\section{*Correspondence to:}

Motohiro Kojima

Division of Pathology, Research Center for Innovative Oncology,

National Cancer Center Hospital East, 6-5-1 Kashiwa-no-ha,

Kashiwa, Chiba 277-8577, Japan

Tel: +81-4-7133-1111; Fax: +81-4-7131-9960

E-mail: mokojima@east.ncc.go.jp 